\title{
TRANSFORMACIONES SOCIO-DEMOGRÁFICAS Y PROCESOS DE GENTRIFICACIÓN EN EL “CENTRO" DE LA CIUDAD DE GRANADA A TRAVÉS DE INDICADORES SIGNIFICATIVOS
}

\author{
Francisco Javier Partal Coca \\ Universidad Nacional de Educación a Distancia \\ Centro Asociado, Plaza de La Magdalena n 1, Córdoba \\ javierpartal@gmail.com \\ Francisco José Morales Yago \\ Universidad Nacional de Educación a Distancia \\ c/ Senda del Rey n 7, Madrid (España) \\ fjmorales@geo.uned.es
}

\begin{abstract}
Resumen: La ciudad de Granada ha experimentado en las últimas décadas importantes cambios demográficos, sociales y económicos que han quedado reflejados a través de la utilización de bases de datos proporcionadas por distintos organismos de la administración pública, destacamos entre ellos el envejecimiento poblacional con relevantes matices entre unas áreas y otras de la ciudad, aumento de la tasa de actividad, crecimiento del número de personas extranjeras o mejoras en el nivel de formación académica con un notable incremento de estudios universitarios finalizados. También se detectan importantes actuaciones de renovación y rehabilitación urbana, un reseñable crecimiento en el número de viviendas disponibles e incremento de viviendas en alquiler y un aumento generalizado en la superficie de las viviendas que también mejoran su grado de confort y equipamientos como la accesibilidad, lo que en definitiva lleva a determinar importantes procesos de terciarización y en algún caso gentrificación, atendiendo a los cambios urbanos contemplados actuales.
\end{abstract}

Palabras clave: Gentrificación, estructura demográfica, Granada, hogar, equipamientos colectivos.

Recibido: 05-03-2019. Aceptado: 04-06-2019. 


\begin{abstract}
Gentrification is a social phenomenon that shows the result in a physical frame as it would be the city of the variations that occurred basically due to the settlement of social classes with greater economic capacity, causing a great impact in the remodeling and value enhancement both in historical centers and in any other area of the city.

In order to know the gentrification processes in the city of Granada, databases provided by the public administration will be used, where after its use there are aspects of gentrification focused on the demographic structure, the comparison between active and inactive population, emergence of new branches within of the labor sectors, changes in the structure of the home and dwellings such as the size of surface or tenure regime. Other notable aspects in this gentrification process will be the improvement of collective facilities such as an elevator, central heating or the level of occupation of the houses. This will lead us to point out that in Granada a gentrification process has been developed with remarkable specificities actually.
\end{abstract}

Keywords: Gentrification, demographic structure, Granada, home, collective equipament.

\title{
1. Introducción
}

Las ciudades son espacios sujetos a cambios constantes tanto en su trazado o morfología urbana como en aspectos demográficos recogidos en la estratificación social de los barrios, la movilidad de los habitantes y el tipo de actividad laboral desempeñada (Bosque, 1988). El presente trabajo pretende analizar a través de diversos indicadores ofrecidos por entidades privadas y administración pública, los cambios sociodemográficos y económicos plasmados en el ámbito urbano de la ciudad de Granada (Jerez, 2002). El primer objetivo ha sido establecer una conexión cuantitativa de la población y su evolución en relación con los procesos demográficos, sociales y económicos. Otro de los objetivos lo constituye el análisis de las características socioeconómicas de la zona urbana analizada de la que se pretende sopesar el grado y la evolución de sus características sociales y económicas que tienen, para poder aplicar teóricamente el concepto de gentrificación (Benach y Mas, 2011), que en el caso de Granada se encuentra localizado en el distrito central o barrio histórico de la ciudad nazarí. Este proceso de gentrificación (Lees, Slater y Wyly, 2008) comienza a darse en un contexto (Sorando y Ardura, 2018), en el que se ha producido previamente un abandono de los centros (Butler, 2007), también se han producido un ascenso de determinados grupos sociales-demográficos y una concienciación gubernamental que se verá reflejada en una serie de actuaciones de recuperación urbana (Díaz, 2014) y patrimonial de entornos que han podido pasar a espacios degradados o en vías de serlo como queda estudiado de forma amplia para el caso de Sevilla (Díaz, 2009, 2011,2013 y 2015) Por lo tanto, se trata de 
un cambio basado en la transformación de determinados espacios urbanos por una serie de grupos sociales que cumplen características con una media de edad entre los 30-50 años, poseen un alto poder adquisitivo, buen nivel cultural y de comportamientos calificados como "urbanitas", es decir, hábitos donde la ciudad se vuelve indispensable, el entorno urbano les ofrece una oferta cultural y social que este grupo de población demanda (Philips, 2004). Asimismo, este tipo de características no deja de ser el resultado del ascenso de nuevos grupos sociales de clase media que han ido consolidando en las últimas décadas del siglo XX También este proceso contribuye con las transformaciones de las estructuras económicas y en las que intervienen distintos tipos de clases sociales. Otro de los factores a tener en cuenta en el concepto de gentrificación son los cambios que se producen a partir de las que se generan dos fases (Rodríguez y Vázquez, 2002): la primera, estos espacios ofrecen una calidad medioambiental destacable o puede tratarse también de unidades que constituyen viejos barrios populares o industriales recuperados a través de ciertas políticas de rehabilitación urbanísticas promocionadas generalmente por los ayuntamientos aunque también la participación privada puede ser relevante.

La enumeración de aspectos demográficos como la estructura de la población a través de la presentación gráfica de pirámides y la evolución poblacional de la zona centro serán determinantes en el conocimiento de los procesos generados en la ciudad que determinan importantes transformaciones en la dinámica demográfica como por ejemplo el aumento de las tasas de envejecimiento y su repercusión en el poblamiento de los barrios. En relación al análisis de los aspectos sociolaborales, estudiaremos la evolución del mercado laboral desde un punto de vista cualitativo, analizando la aparición de un progresiva especialización laboral y una formación más cualificada por un mayor acceso a estudios universitarios, lo que generalmente repercute en la aparición de una población de mayor capacidad adquisitiva por el acceso a trabajo mejor remunerados y que significaría la aparición del término: gentrificación estratégica (Fion, 2016).

También abordaremos el fenómeno de la inmigración como un realidad consolidada en las últimas décadas que ha dado a la ciudad la oportunidad de contribuir al crecimiento demográfico y la ocupación de un importante número de viviendas, hecho que repercute directamente en cambios en el número de miembros en cada hogar, régimen de tenencia o mejora en los equipamientos colectivos como la dotación de ascensores en los edificios o más de carácter individual como la instalación de calefacción en hogares.

\section{Marco teórico}

Las transformaciones sociodemográficas en las ciudades son objeto de estudio en diversas disciplinas académicas como la sociológica, demografía o antropología. Para el caso de la ciencia geográfica la plasmación de estas transformaciones en el paisaje evidencian objetos de estudio como los cambios morfológicos, políticas de renovación y rehabilita- 
ción o procesos de gentrificación que implican una transformación basada en la ocupación de algunos sectores de las ciudades por una serie de grupos sociales (Hackworth y Smitth, 2010) que cumplen características como la de tratarse de sectores de población relativamente joven o mediana (entre los 30-50 años), poseen alto poder adquisitivo, elevado nivel cultural y el mantenimiento de una serie de comportamientos calificados como "urbanitas", es decir, hábitos donde la ciudad se vuelve indispensable, ofreciendo una oferta cultural y social que este sector de población demanda (Sargantal, 2000).

Otras razones por las que se produce la ocupación de dichos grupos sociales en ciertos sectores de la ciudad es la distancia a los lugares de trabajo, generalmente vinculados con el centro de la ciudad, también aparecen razones de prestigio ambiental y arquitectónico así como las facilidades en la accesibilidad tanto motorizada como a pie. La concentración de servicios especializados, la abundancia de oferta comercial y su variedad, así como la diversidad de actividades contribuyen a que la zonas centrales de la ciudad sean espacios atractivos (García y Sequera, 2013).

Una de las consecuencias directas del fenómeno de la gentrificación lo constituye la "expulsión" de las clases sociales que poseen unos bajos ingresos (Guadalupe, 2016) ya que se producen transformaciones sujetas a políticas de renovación y rehabilitación del centro de la ciudad y que, consecuentemente, producen un encarecimiento del suelo (Lebreton y Mougel, 2008). A su vez, estos factores producen una revitalización del centro que puede ser tanto planificada como espontánea como es el caso de algunas ciudades de Latinoamérica (Gómez y Villar, 2015). También el turismo es intenso en estos espacios centrales de la ciudad (Hiernaux y González, 2014), lo que conlleva hacia una importante ocupación de espacios dedicados al ocio, la restauración o el comercio, en Andalucía los ejemplos son muy evidentes (Feria, 2015).

La gentrificación ha generado cambios sociales (Lehman, 2008), pero también los cambios sociales han influido en ella, autores como Hamnett (2003) vincula este proceso con el progreso de la sociedad industrial a la actual. En su estudio sobre la gentrificación que se produce en Londres ${ }^{1}$ profundiza en los procesos económicos que producen un incremento del nivel de vida y el impacto de este en el mercado de la vivienda. Pone acento en la influencia de otros factores como la emigración o las jubilaciones. Otros autores como Donzelot (2004) asocian los cambios sociales con las distintas velocidades las cuales se basan en la relegación, la periurbanización y la gentrificación. Se produce una relegación cuando los residentes se ven obligados a realizar cambios por falta de elección. Estos cambios pueden derivar en espacios degradados los cuales necesitan distintos tipos de actuaciones para ser solucionados ${ }^{2}$.

1. Hamnett, C.: Gentrification and the Middle-class Remaking of Inner London, 1961-2001. UrbanStudies, Vol. 40, № 12, 2401-2426, November 2003.

2. Donzelot, J.: La ville à trois vitesses: relegation, périurbanisation, gentrification. Esprit. № 303 (3/4) MarsAvril 2004, pp. 14-39. 
Se puede entender el proceso como una solución para los problemas de degradación y abandono de los centros históricos (Reyes, 2017). En este contexto de debate, distintas posturas y críticas destaca la visión crítica de Slater $^{3}$ (2006) pone acento en la acción salvadora de la gentrificación de las ciudades como se venía manifestando por los académicos. Asimismo, destaca la concentración en los estudios de las clases medias y los beneficios que puede producir restando importancia a la concepción del desplazamiento, pero otra de las razones que aporta es la implicación de las políticas públicas en la era neoliberal que ha supuesto la intervención del Estado en las zonas degradadas. Por ello, considera que las expectativas de la gentrificación son el verdadero salvador de nuestros vecindarios del centro de la ciudad, incluso si estas declaraciones pueden llevar contrastes políticos e ideológicos ${ }^{4}$.

El espacio gentrificable, asociado a un barrio que ha entrado en un proceso de degradación y deterioro debido a su abandono, está asociado hacia habitantes de escaso poder adquisitivo o con ingresos bajos o moderados (Sequera, 2014 y 2015). Históricamente, los barrios obreros gentrificables han sido víctimas de la degradación ya que su población, de clase obrera, ha sido la población más vulnerable al sentirse desplazada por sus escasos recursos ante la revalorización de la zona como se indica en el barrio del Raval de Barcelona (Alba, 2001) o Madrid (García, 2014), (Muñoz, 2009) y (Abellán, 2014). Por ello, desde un primer momento el inquilino en su origen poseía bajos recursos económicos antes de la rehabilitación de la vivienda lo que le permitía vivir en una vivienda degrada cuyo alquiler era bajo por la situación en la que se encontraba. Al ser rehabilitadas las viviendas, el inquilino original no puede permitirse mantener su vivienda por la revalorización de la misma y posterior revalorización de la zona. Además de la clase obrera, se encuentran otros grupos sociales que vienen representados por clases sociales jóvenes, generalmente relacionados con lo bohemio y que tiene interés en hacer uso del centro urbano por los servicios que ofrece este. Estos grupos sociales también han generado un cambio demográfico en los centros y nuevas formas culturales (Valencia, 2010).

Castells 5 (1993) destacó la comunidad gay como generadora del proceso de gentrificación en San Francisco cuya función estuvo delimitada por la exclusividad y el control de la localización en las zonas centrales de la ciudad. Por su parte, destaca el papel de bohemio mencionado por expertos como Ley ${ }^{6}$ (2003) concebido como elemento

\footnotetext{
3. Slater, T.: The Eviction of Critical Perspectives from Gentrification Research. International Journal of Urban and Regional Research.Volumen 30.4. December 2006, p. 752.

4. "The prospect of gentrification being the true saviour of central city neighbourboods, even if these statements were guided by contrasting political ideologies" de Slater, T.: The Eviction of Critical Perspectives from Gentrification Research. International Journal of Urban and Regional Research. Volumen 30.4. December 2006, págs. $737-757$.

5. Castells, M.: The City and the Grassroots: A Cross-cultural Theory of Urban Social Movements. Ed. Edward Arnold. London. 1983, pp. 170-185.

6. Ley, D.: Artists, Aestheticisation and the Fiel of Gentrification. CarfxPublishing. UrbanStudies, Vol. 40, № $12,2527-2544,2003$.
} 
vinculador con la industria cultura joven relacionada con el centro y los servicios que ofrece, donde atribuye el papel "creador" de los artistas y su importancia en el campo de la gentrificación y la intervención de la cultura en este (García, Ramos, Salvadó y Sorando, 2017) que contrarresta los efectos de la desigualdad ante las políticas urbanas desarrolladas (Arbaci y Rae, 2014) en una sociedad que tiende a la globalización y por tanto uniformización de normas y hábitos de vida (Perren y Cabezas, 2016).

\section{Metodología}

En la metodología aplicada en el presente trabajo se emplean de forma simultánea y complementaria datos cuantitativos suministrados por diversas administraciones públicas como el INE, Catastro de Urbana o Ayuntamiento de Granada (Aguilera et al., 2003). Se combina junto a la necesaria búsqueda documental, un trabajo de campo que ha consistido en examinar el espacio objeto de estudio que se centra en el conjunto urbano de la ciudad, así como un trabajo de observación en el que se tomó en cuenta las transformaciones producidas a lo largo del tiempo respecto al desarrollo urbano. Las distintas etapas de investigación llevadas a cabo han repercutido en la consulta de documentos sobre el tema tratado, basados en datos estadísticos que constituyen una valiosa fuente de información proporcionando una interpretación y lectura sobre el tema, realizando operaciones analíticas y sintéticas que repercuten en una crítica interna y externa de los datos y documentos recopilados.

Una de las principales fuentes de información la constituye el Censo de Población y Vivienda del Instituto Nacional de Estadística (INE) de los años 1991, 2001 y 2011, aunque estos datos no se hicieron públicos hasta final de 2014. La importancia del Censo del año 2011, muestra de forma exponencial la implicación económica en la sociedad de la coyuntura causada por la crisis de 2008, cuyos efectos se dejaron sentir a partir de principios de 2009 hasta al menos 2011, conllevando un declive económico del sector inmobiliario, así como una reducción del consumo y un aumento del paro que tuvo su máximo reflejo en la tasa más alta con un 28,78\%.

\section{Análisis de datos que evidencian cambios significativos}

\subsection{Aspectos demográficos: estructura y características relevantes}

El análisis de la estructura demográfica en Granada (Bosque, Bosque y Gutiérrez, 1993) resulta relevante para determinar los sectores de población caracterizados por grupo de edades, para entender procesos como el envejecimiento poblacional es necesario determinar la evolución de los grupos de edades de la ciudad y comprobar me- 
diante la comparación si se produce dicho envejecimiento poblacional, una de las figuras eficaces para medir y comparar la estructura de la población la constituye la pirámide de población. Estableciendo una comparativa que refleja la evolución de las tres pirámides de población se pueden determinar comportamientos demográficos, la base de la población tiende a estrecharse aunque en el año 2011 se dilata levemente debido a la recuperación de la tasa de la natalidad en los últimos años con respecto a la pirámide de 1991. Otra tendencia es el estrechamiento de los grupos de edades jóvenes, ello indica una menor población de grupos de edades hasta los 20-24 años. También se aprecia agrandamiento en la base central lo que supone un aumento de población adulta, el cual produce una forma abombada por la parte superior, lo que indica un incremento de la edad media de la población. No obstante, el rasgo más destacable en la parte superior de la pirámide es el aumento de la población mayor de 65 años, la población mayor femenina es otra de las características visualización de las tres pirámides. A rasgos generales indicamos que la pirámide de la ciudad de Granada, tiene una base estrecha que tiende a conservarse, la parte central inferior (población joven) tiende a reducirse, mientras que la parte central superior (población adulta) tiende a agrandarse, de hecho se habla de la población anciana como un colectivo que necesita ser atendido y con importantes cuestiones de dependencia (Compán y Sánchez, 2005).

Analizando la evolución de las pirámides, respecto a su forma, se observa como la cima tiende también a expandirse, parte en la que se produce un importante distanciamiento de la población femenina sobre la población masculina.

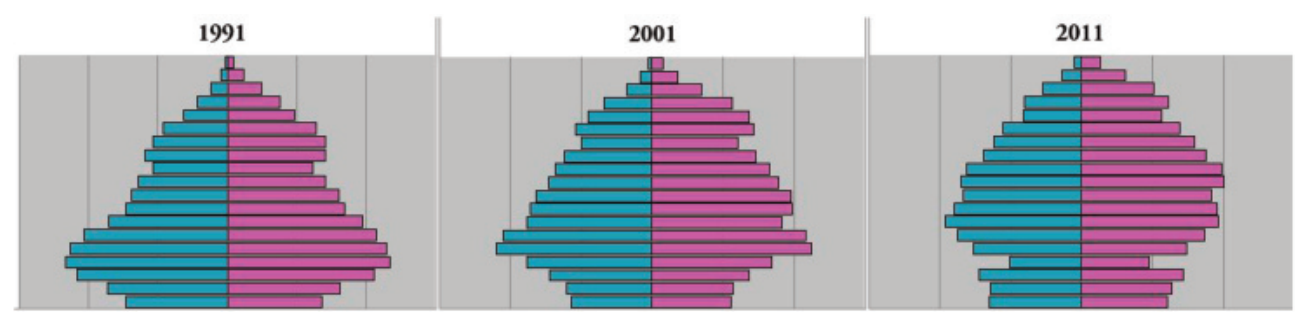

Figura 1. Pirámides de población de Granada (1991-2011).

Fuente: Instituto de Estadística y Cartografía de Andalucía. Elaboración propia.

La población joven se reduce mientras que la población adulta aumenta, además se producen un envejecimiento pronunciado con una preeminencia de la mujer sobre el hombre en este grupo de edad. La modificación de la estructura de la pirámide obedece a múltiples factores, entre otros, la reducción de la fecundidad a niveles inferiores del remplazo generacional, la disminución de las tasas de mortalidad y el aumento de la esperanza de vida y de la edad media. 
Si se analiza el número de personas mayores de la ciudad de Granada se observa un considerable aumento en el periodo cronológico estudiado. Así, en 1991 la población mayor de 65 años asciende a 31.557 con un predominio de las mujeres (19,51\%) sobre los hombres (12,04\%), lo que supone un 12,3\% sobre la población total de ese año. En 1996 se produjo un incremento de la población mayor de 65 años con 35.771 personas y un descenso de la población, lo que supone un incremento considerable de la tasa que llega al 14,5\% sobre la población total. También ese año se mantiene la preponderancia de la población femenina mayor (22.052) sobre la población masculina mayor (13.716). En 2001 la tendencia se consolida con un aumento de 41.446 personas mayores de 65 años, cifra que supone una tasa de $17,03 \%$ y una tendencia de la población femenina mayor (22.585) sobre la población masculina (14.735). En el año 2011 la cifra aumenta considerablemente con un total de 44.764 , lo que supone un total de un 18,6\% de personas mayores de 65 años con respecto a la población total, con importantes diferencias entre la población mayor femenina (26.688) sobre la población mayor masculina (16.897).

Por otra parte, si se compara con la pirámide de la población actual, se puede observar la consolidación del envejecimiento paulatino que se había venido estableciendo durante los años anteriores. Dicho envejecimiento se refleja en el aumento de las edades adultas en las que las mujeres superan de forma notable el número de hombres mayores. Asimismo, por ejemplo mientras en las edades más recientes hay una tendencia de niños (4.912) sobre niñas (4.578) en las edades del grupo de 0 a 4 años, en el grupo que supera los 85 años se perciben una exponencial diferencia entre hombres (2.209) y mujeres (5.089).

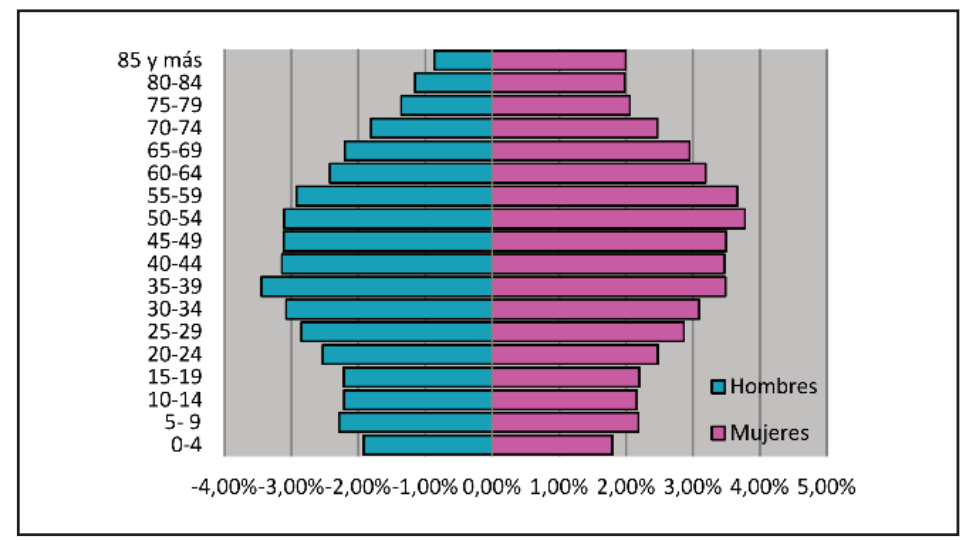

Figura 2. Pirámide de población de la ciudad de Granada 2017. Fuente: Instituto de Estadística y Cartografía de Andalucía. Elaboración propia. 


\subsubsection{Demografía actual de los distritos del centro}

El centro de la ciudad viene determinado especialmente por el distrito histórico y parte del barrio del Albaicín. La pirámide del distrito Centro, posee una forma de hucha y regresiva, se caracteriza por mostrar un bajo porcentaje en la base procedente de población juvenil, y el alto porcentaje de la población adulta, que resulta destaca especialmente a partir de los 25 años. En ese sentido se hace evidente la cantidad de la población adulta joven entre 25 y 40 años de edad, destaca la presencia de sectores de población joven en el distrito debido a razones de proximidad a los lugares del trabajo, motivos de prestigio ambiental y arquitectónico.

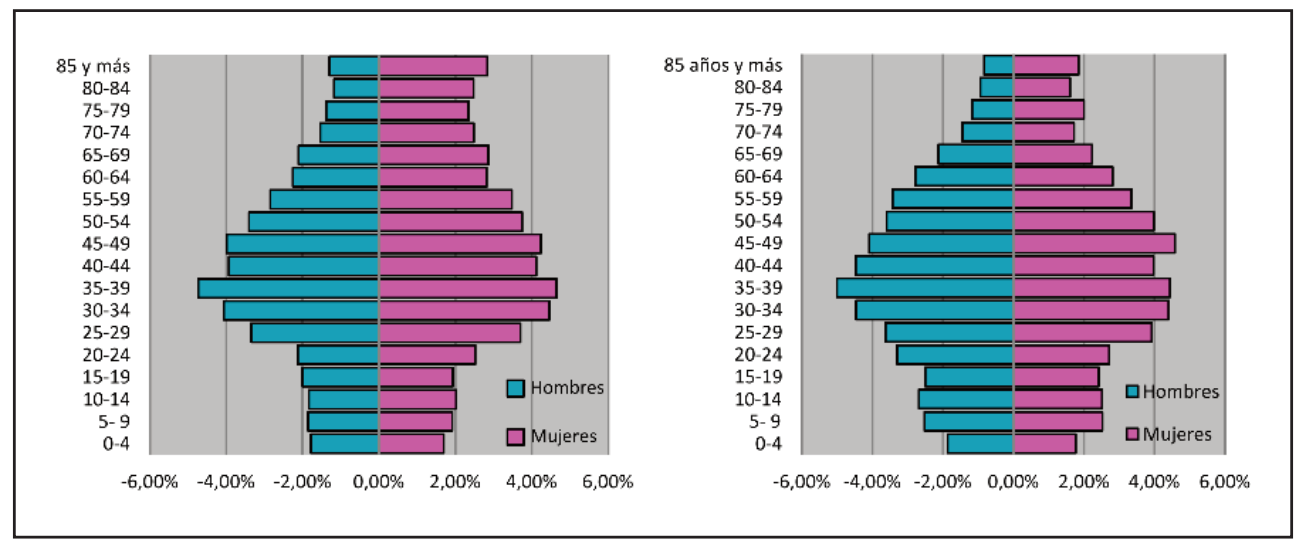

Figura 3. Pirámides de población de distrito Centro y barrio del Albaicín (2015).

Fuente: Instituto de Estadística y Cartografía de Andalucía. Elaboración propia.

Por otra parte las diferencias de la población femenina sobre la masculina se van incrementando conforme se avanza en los grupos de edad. En este caso destaca la población femenina en los últimos grupos de edad, a partir de los 70 años con una diferencia importante, por ejemplo en el grupo de edad superior a 85 años las mujeres son un total de 682 frente a 311 de los varones.

En la pirámide de población del Albaicín (Duque, 2016), distrito vinculado con el centro de la ciudad se pueden observar aspectos característicos al ser uno de los barrios más antiguos de Granada y de los menos poblados (Fernández y Jiménez, 2005), destaca su característica forma de hucha o tulipa, abombada en el centro de la forma piramidal. Esta forma se vincula con unas tasas bajas de natalidad y mortalidad reflejando una población regresiva. Respecto a los sexos se percibe una mayor población masculina en edades tempranas, sin embargo, la población masculina se reduce a medida que se va avanzando en 
edad, superando de esta forma la población mayor femenina a la población mayor masculina con una notable diferencia. Lo que indica una mayor tasa de mortalidad en edades maduras de la población masculina que de la población femenina.

En comparación con la pirámide del distrito Centro, se puede observar que existe una preeminencia de mujeres sobre hombres, y una reducción respecto al distrito centro de personas mayores de 65 años. Sin embargo, se observan ciertas similitudes como base y cima estrechas que determina una forma parecida de hucha pesar de que en la pirámide del distrito Centro se presenta un mayor estrechamiento de la base, lo que determina una menor población infantil relacionada con el establecimiento de un mayor número de familias en el Albaicín que el anterior distrito.

\subsubsection{La zona centro delimitada según los Censos}

La selección de las secciones se ha determinado para poder establecer un criterio objetivo de lo que supone "centro" de la ciudad para, posteriormente, extraer datos de los Censos que aporten información relacionada con los procesos poblacionales y otros elementos como la posibilidad de iniciarse procesos de gentrificación u otras dinámicas (Romero y Romero, 2017). La siguiente figura muestra la relación de las zonas seleccionadas del centro de la ciudad para su posterior estudio, análisis y comparativa de la información que ofrecen los Censos. Remitiéndonos a los criterios administrativos, la ciudad de Granada está dividida en ocho distritos (Albaicín, Beiro, Centro, Chana, Genil, Norte, Ronda y Zaidín). A pesar de estas divisiones establecidas, estos distritos administrativos no corresponde en sus totalidad con los criterios llevado a cabo por los Censos de Población y Viviendas (divididos en nueve distritos, a su vez subdivididos en 185 secciones).

Teniendo encuentra el espacio seleccionado para la delimitación de la llamada zona "centro" (Ruiz y Barbosa, 1997) esta selección incluye administrativamente partes de los distritos Centro en su mayoría pero también secciones de Realejo, Albaicín y Ronda. Todos estos distintos aportan un conjunto de territorios a lo que comúnmente se le denomina "centro". No obstante, esta selección no deja de ser una muestra de lo que podría entenderse como centro, más allá de la limitación que implica una selección administrativa. 


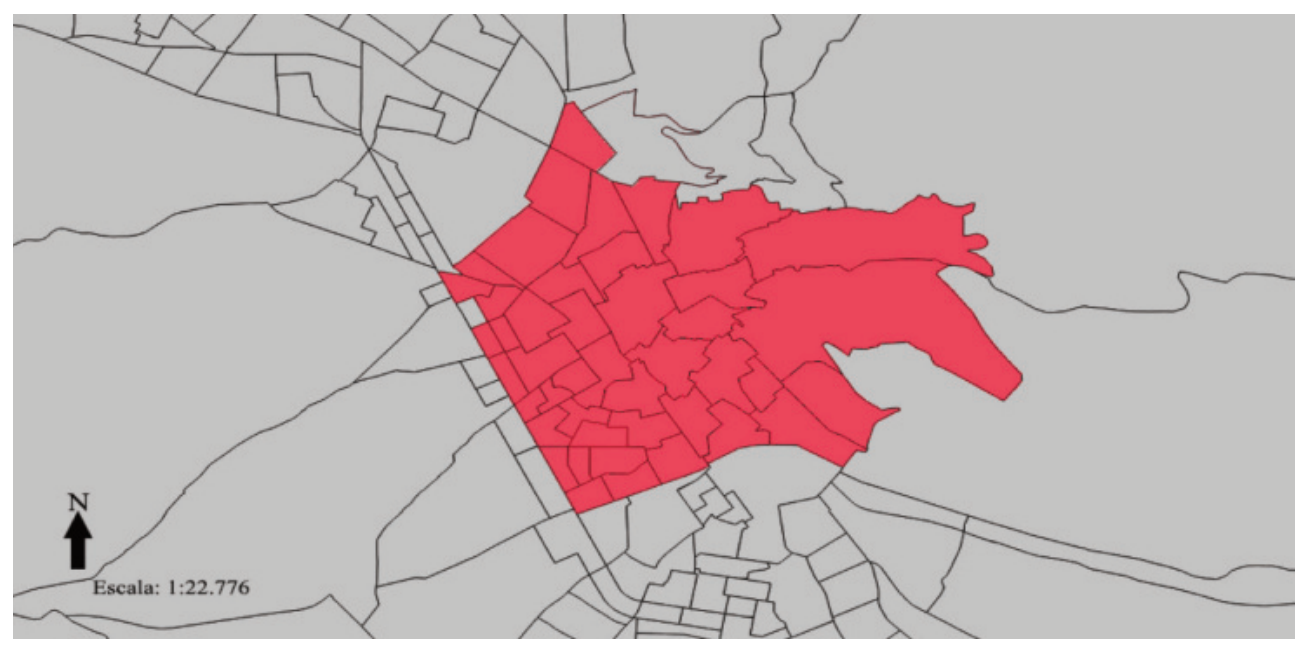

Figura 4. Distritos zona centro.

Fuente: INE. Elaboración propia.

\subsubsection{Evolución demográfica de la zona centro}

Analizadas las dos pirámides de población actuales de la zona centro (Centro y Albaicín), así como aclarada la cuestión de la delimitación territorial en cuanto al concepto de centro se refiere, conviene repasar la evolución demográfica de la zona centro según los datos del Censo de población y vivienda. En este punto se analizarán las pirámides de población de la zona centro anteriormente señalada de los años 2001 y 2011 para establecer una evolución.

Es importante destacar que estas pirámides están construidas en base a los datos facilitados por el Censo de los distritos y secciones mencionadas anteriormente, por lo que conviene resaltar que no se trata de un distrito sino de una zona céntrica que ocupa el distrito Centro y el distrito Albaicín en menor medida. Este criterio territorial será el utilizado para analizar los aspectos de los siguientes apartados de este trabajo.

Otro dato que mide el envejecimiento de la estructuras es la edad media, mientras que en 2001 la edad media de los residentes de la zona centro era de 43 años (40,3 para varones y 45,3 para las mujeres), en 2011 aumenta la edad media en algo más de un año situándose en 44,5 años (41,8 para hombres mientras que para mujeres se sitúa en 46,7). Podemos determinar que se produce un envejecimiento tanto en hombres como en mujeres del periodo de 2001 al 2011, y por lo tanto un aumento de la edad media en la zona centro de la ciudad. También hay que destacar que se produce un aumento de población en casi mil personas ya que en 2001 son 51.358 personas las que residen 
en el centro mientras que en 2011 son un total de 52.210 personas. Algo que puede reflejar la rehabilitación de zonas y edificios habilitados para la vivienda, una muestra del proceso lento pero efectivo de recuperación residencial en el centro de la ciudad.

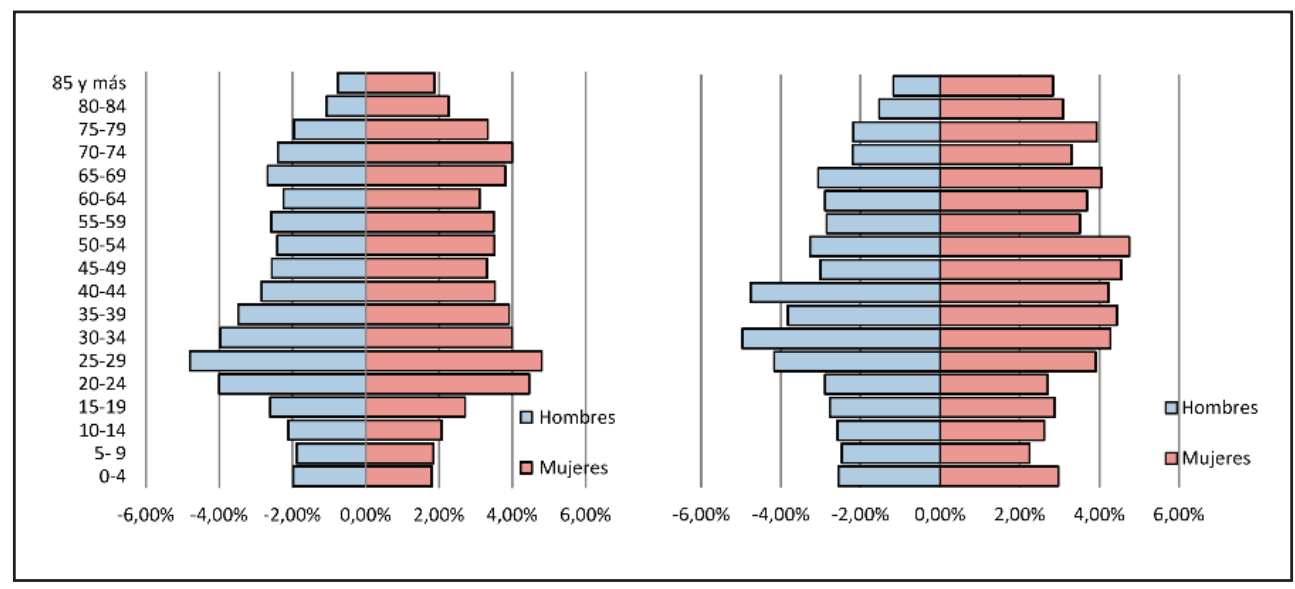

Figura 5. Pirámides de población de la zona centro (2001-2011).

Fuente: INE. Elaboración propia.

Respecto a la población mayor de 65 años, en 2001 residían un total de 10.276 lo que suponía un 20\% de la población total de la zona centro ese mismo año. Por otra parte, en 2011 residían 10.020 personas mayores de 65, lo que implica un porcentaje de un 19,32\% sobre la población total. Este dato ofrece información de gran importancia ya que, como se puede observar en la evolución de la edad media, hay un aumento de la edad media en los residentes de la zona centro desde 2001 a 2011, sin embargo, se produce un descenso en los residentes de la zona mayores de 65 años con así un $1 \%$ de diferencia a pesar del aumento de población en la zona centro. Estos factores indican un aumento de población adulta a partir de 35-40, sectores de población que posee un trabajo y mayor poder adquisitivo que la población mayor de 65 años.

\subsection{Aspectos sociolaborales}

En este apartado se han analizado aspectos como la evolución del mercado laboral, estructura del hogar y vivienda, indicadores que ayudarán a conocer mejor las características de la población y los cambios producidos en las últimas décadas. 


\subsubsection{El mercado laboral}

Para analizar el alcance de la actividad laboral y sus implicaciones, resulta de especial relevancia establecer una comparativa entre la población activa y la inactiva a través de la información que nos proporcionan los Censos de población y vivienda. Así, en 2001 la población de activos se hallaba en 21.572 personas, mientras que la cifra de personas inactivas ascendía a 29.786 de las 51.358 personas que habitaban en la zona centro de la ciudad de 2001. Por otro lado, de las 52.210 personas que residían en el centro de la ciudad según el Censo de 2011 eran las 26.100 las personas activas, mientras que 26.110 personas eran inactivas. Por lo que si se comparan los dos datos se producen un incremento del número de personas activas en el centro de la ciudad. Como se puede observar en la siguiente figura se produce un incremento en la relación de personas activas sobre las inactivas porcentualmente.

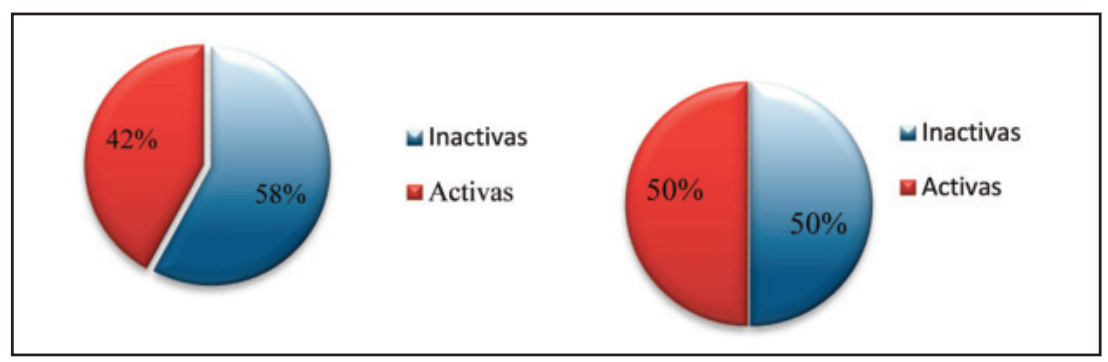

Figura 6. Relación de personas activas/inactivas (2001-2011).

Fuente: INE. Elaboración propia.

Otro dato relacionado es la tasa de actividad media, según el INE, este valor se entiende como la relación entre el total de la población activa de quince años o más edad (un total de 21.572 personas en 2001 y 26.100 en el año 2011) y la población total de 16 años o más edad (un total de 45.595 personas para 2001 y 45.350 personas para 2011). En este caso la Tasa de Actividad Media es de 61,5\%, lo que significa que de cada 100 personas de dieciséis años o más, 61,5 personas tienen empleo o lo están buscando de forma activa. De esta forma se calcula que la tasa de actividad media en 2001 era del $47,3 \%$, y en 2011 correspondía a un 57,5\%. Por lo que se observa que la tasa de actividad media aumenta en casi un $10 \%$ en un periodo de diez años.

Otra tasa interesante a destacar relacionada con los aspectos económicos y demográficos es la tasa de dependencia que se entiende como la relación entre las personas dependientes comprendidas en menores de 15 años y mayores de 65 años sobre la población en edad de trabajar que se sitúa entre 15 y 65 años. Resulta significativo analizar esta tasa pues indica tanto la dependencia económica como el incremento de ciertos sectores de población que se ha producido en el plazo de diez años. En 2001 
la población con dependencia ascendía a 17.686 personas, mientras que la población en edad de trabajar se situaba en 33.672, la tasa de dependencia resulta en un 52,5. En 2011 eran 19.000 personas las localizadas en el grupo de las personas dependientes, por su parte eran 33.210 personas las que se localizaban en edad de trabajar, por lo que la tasa de dependencia resultaba 57,2\%, ello indica que la población dependiente aumenta en un periodo de diez años. Si bien se produce un leve incremento de 11.923 personas mayores de 65 años en 2001 a 12.140 personas, es en menores de quince años donde se produce un destacable incremento de población ya que de 5.763 menores se pasa a 6.860 personas, lo que indica un incremento de natalidad, un aumento de población en edad fértil que muestra un incremento de familias.

En relación a las ramas de los sectores laborales de 2011, la tónica sigue siendo la misma; una preeminencia del sector servicios que sobresale sobre los demás sectores, sin embargo se produce un incremento del sector servicios en el número de personas que trabajan en dicho sector produciéndose un incremento de 2.143 personas en el plazo de 10 años. Lo que indica una creciente terciarización de la zona, algo que se relaciona directamente con procesos de gentrificación en el centro de la ciudad. Hay que tener en cuenta que al producirse una revalorización de las zonas centrales, se incrementa el circuito donde las dinámicas de terciarización, aumento de población, cambio poblacional, entre otros factores, así como el incremento del precio forman parte de los procesos de cambio en el centro de la ciudad. El incremento y la preponderancia del sector terciario se consideran factores indispensables para la creación de un proceso de cambio que genera una nueva estructura económica, profesional, laboral y de ingresos. El incremento del sector terciario y de sus trabajadores tradicionalmente se asocia a un proceso de cambio en el centro donde el sector secundario había sido desplazado por el sector terciario, que ha estado asociado a funciones como profesionales libres, funcionarios, administración, gestión, secretaría, comercio, docencia, sanidad, entre otros.

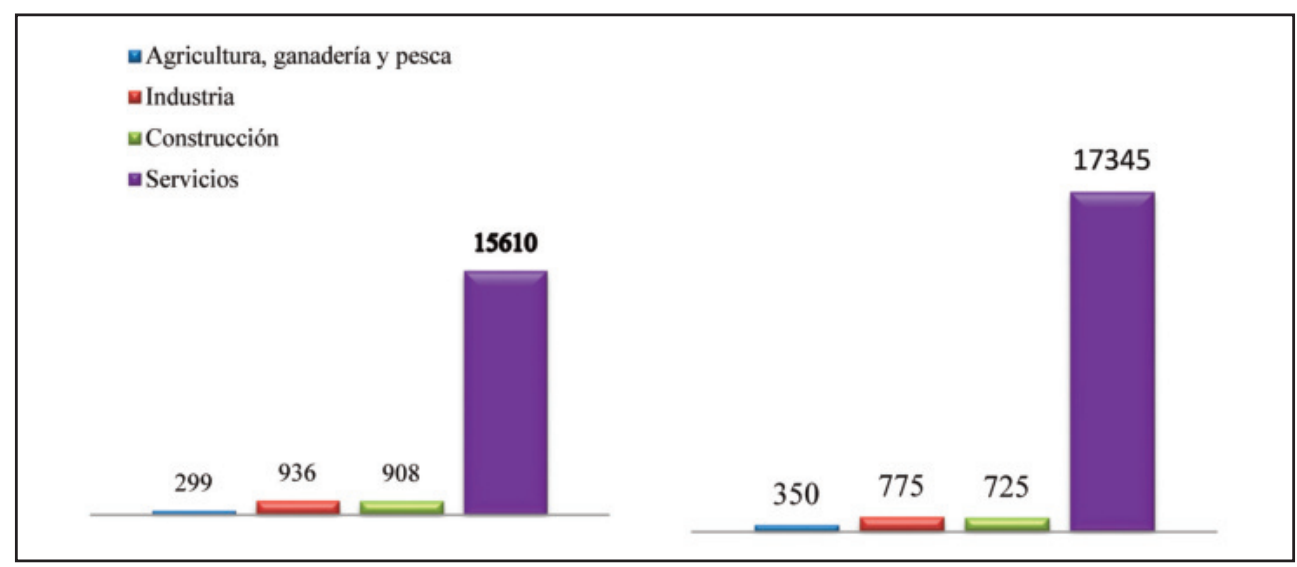

Figura 7. Evolución de ramas de sectores laborales (2001-2017).

Fuente: INE. Elaboración propia. 


\subsubsection{Educación y formación profesional}

Las dinámicas poblacionales suelen estar asociadas a cambios de comportamiento que se originan en transformaciones demográficas, el proceso de gentrificación se asocia a personas con comportamientos "urbanitas" destacando especialmente una tendencia hacia una estructura social con una alta formación profesional y estudios avanzados. Se puede observar que resulta reducida la proporción de personas sin estudios, este sector se reduce de 4.820 personas a 2.685 en un periodo de tiempo de tres décadas. Se reduce también significativamente el número de personas que posee la educación primaria pasando de 7.762 personas a 4.010. También se aprecia una leve reducción en cuanto a los estudios de secundaria, disminuyendo de 17.939 a 16.690. Sin embargo, el dato más llamativo en esta comparativa lo constituye el significante aumento de población que posee estudios universitarios ampliándose en más de cuatro mil personas ya que de 17.063 personas que poseían algún título universitario en 2001 se aumenta a 21.200 personas con título universitario o superior. El Censo de 2011 existe una categoría "no aplicable" que constituyen datos desconocidos ( 7.295 personas) que pueden variar los datos y consecuentemente las interpretaciones y las conclusiones que permiten teorizar sobre este aspecto.

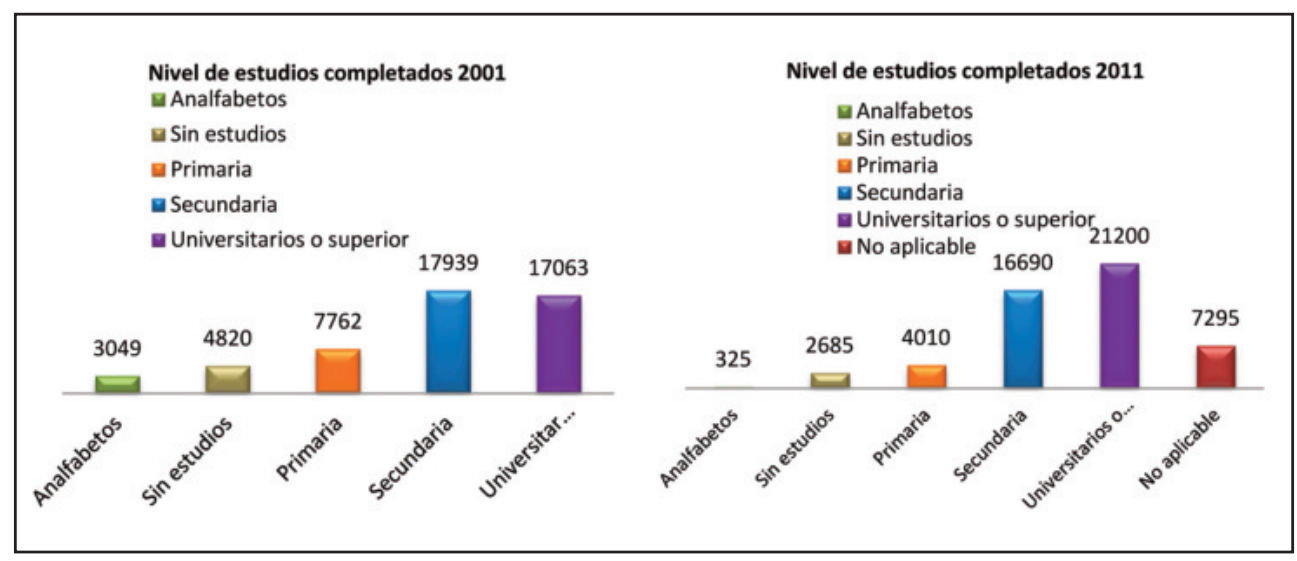

Figura 8. Evolución del nivel de estudios completados en Granada (2001-2011).

Fuente: INE. Elaboración propia.

Analizando el nivel de estudios completados, se puede observar que un $12 \%$ de la población residente en el centro de la ciudad ha cursado estudios en Derecho y Leyes (destaca esta rama con un total de 6.185 casos contabilizados), seguida de la rama de Salud y Servicios sociales ( 4.730 casos), en tercera posición se encuentra paralelamente las ramas de Educación (con un total de 3.500 casos contabilizados) y las rama de Ar- 
tes (cuya cantidad se eleva a 3.340 casos). Esta rama destaca ya que en muchos casos la gentrificación ha estado impulsada por sectores sociales con comportamiento "urbanitas", a menudo calificados de "bohemios" que fácilmente podrían vincularse a la rama de estudios de artes. Estos sectores bohemios se sienten atraídos por la oferta cultural del centro y, en ocasiones, suele estar asociado a extranjeros que se asientan en el centro de la ciudad y poseen comportamientos más "alternativos" que los sectores de población de residentes tradicionales. Por ellos esta rama merece una especial mención.

Merece atención las ramas de estudio con menos casos contabilizados (160) que se trata de la rama de Agricultura, Ganadería, Pesca y Veterinaria. Curiosamente, esta rama es la asociada a sector primario, en este sentido las ramas de los estudios parecen apoyarse en la teoría de una tendencia a la "terciarización" del centro que no solo se reflejan en un ámbito económico y una transformación sectorial del centro urbano sino en la relación que conlleva con la rama de los estudios, es lógico que en un entorno urbanístico regido por el sector terciario la demanda de población especializada en el sector primario sea menor.

El recuento del Censo a menudo puede generar inconvenientes, uno de los más usuales lo constituye la falta de datos de algunas estadísticas. En este caso se aprecia la existencia de la clasificación "no aplicable" con un 54\% sobre el área del nivel de estudios completados. Resulta merecedora de atención ya que los datos desconocidos constituyen un amplio sector que podría variar las interpretaciones de este estudio.

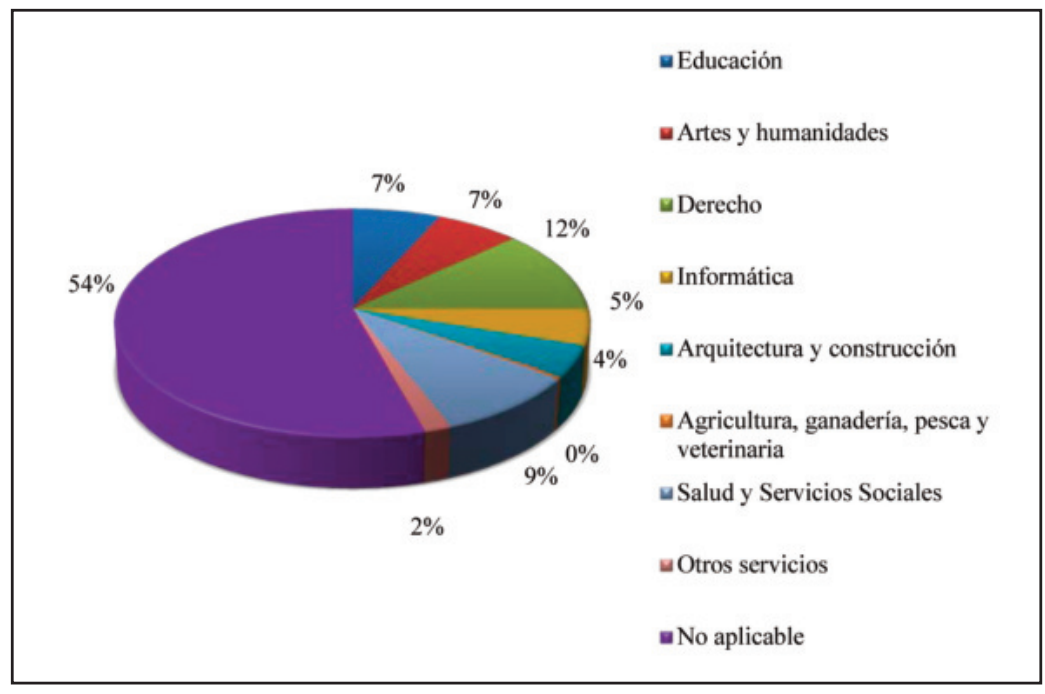

Figura 9. Nivel de estudios completados (2011).

Fuente: INE. Elaboración propia. 
Un dato interesante ofrecido por el Censo de población y vivienda de 2011 es el detalle del nivel de estudios de la población ocupada (19.195) que reside en la zona centro de la ciudad. Como se puede observar la mayoría de la población ocupada posee algún Grado Universitario o Licenciatura constituyendo un 36\% del total con 6990 casos contabilizados. A este sector le sigue la población que posee algún tipo de Diplomatura (también arquitectura técnica) con un total de 2.720 casos equivaliendo al $14 \%$ sobre el total de los casos, este sector es seguido por la población que posee el título de Secundaria (entendido también como Bachiller o BUP). Por otro lado destaca el pequeño sector que compone los analfabetos (95 casos) y las personas sin estudios, es decir, que saben leer y escribir pero que no poseen ninguna titulación (325 casos). Estos casos contrastan con el otro extremo en cuanto a la formación se refiere, por un lado aquellos que poseen algún Máster oficial universitario (a partir de 2006) o Especialidades Médicas o análogas con un 6\% (1.160 casos); y por otro, los que poseen un Doctorado, un 11\% (con un total de 2.075).

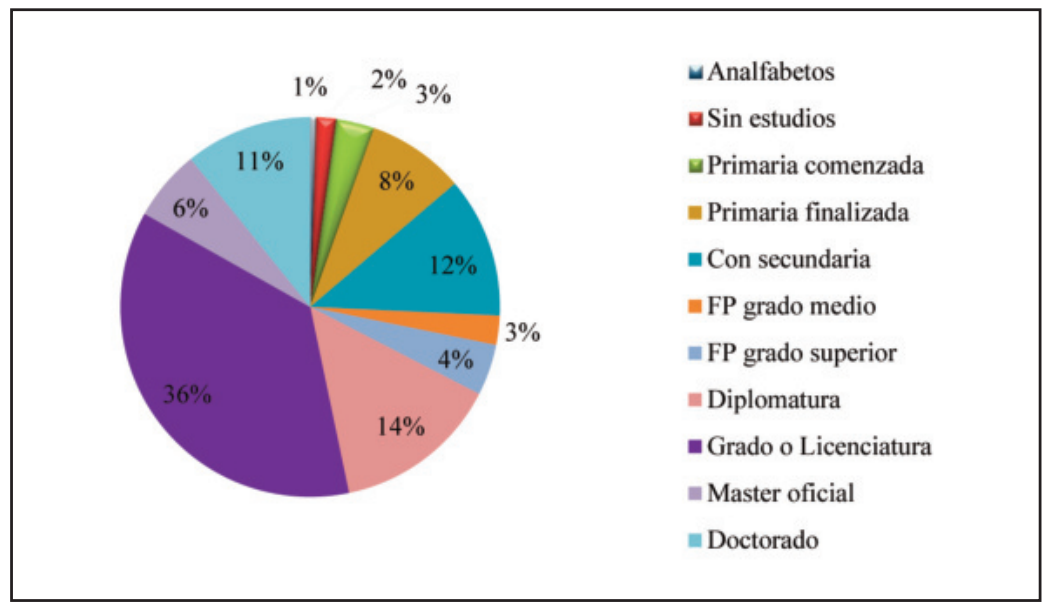

Figura 10. Nivel de estudios de ocupados (2011).

Fuente: INE. Elaboración propia.

En relación a los estudios universitarios en el distrito centro aparece un porcentaje mucho mayor de personas que en otros de la ciudad, lo que resulta significativo para conocer mejor las características del centro urbano de Granada. 


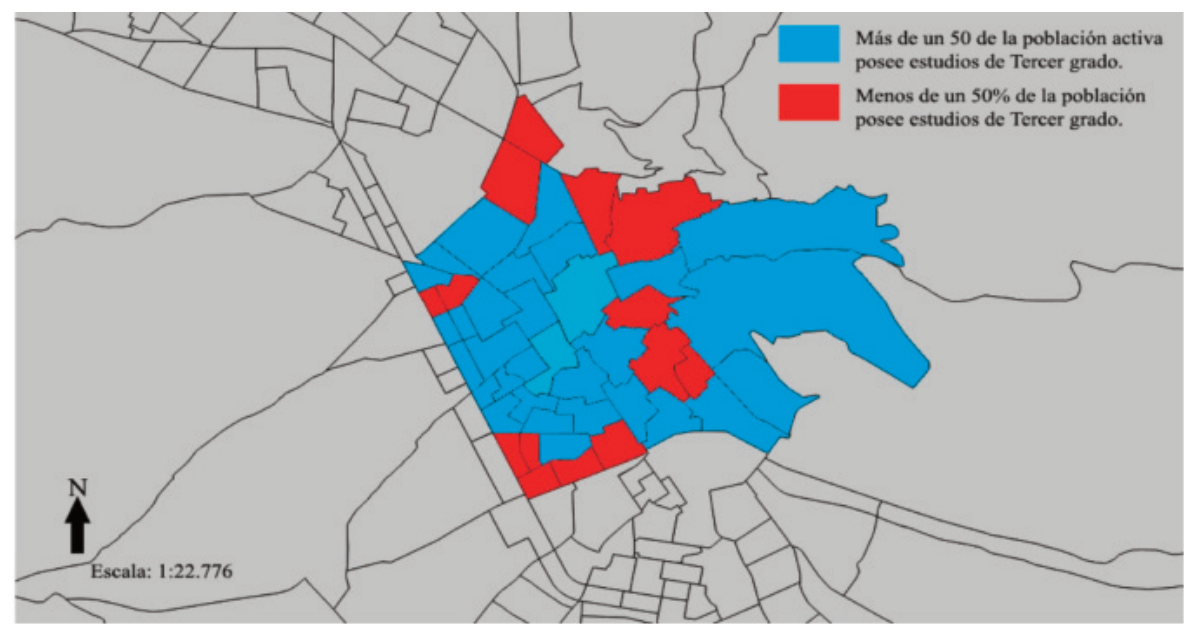

Figura 11. Mapa estudios universitarios centro por secciones censales de 2011.

Fuente: INE. Elaboración propia.

\subsubsection{La población inmigrante}

Otro aspecto destacable en cuanto a la transformación social de un espacio es el relacionado con el fenómeno de la inmigración. El análisis de los residentes extranjeros permite observar, por un lado, el origen y la tendencia a la acumulación de residentes extranjeros que dependiendo de su lugar de origen puede contribuir a la transformación económica de una zona urbanística; y por otro, la vinculación a la revalorización del centro como foco de atracción extranjera que se halla en total conexión con la importancia del turismo. Este factor no solo constituye un rasgo social y económico, sino que puede generar transformaciones como el encarecimiento del suelo e, incluso de los bienes de primera necesidad en una zona en particular. La vinculación del turismo con la población extranjera residente se consolida, de alguna manera, por la fama que genera un paisaje urbano por su valor patrimonial, histórico e incluso emocional (Zárate, 2012). El turismo también puede generar modificaciones en el paisaje a nivel estético, las imágenes paisajisticas tradicionales se han visto degradadas por una tendencia a la apertura de grandes cadenas mundiales vinculadas a la globalización. Estas franquicias homogeneizan los paisajes y contribuyen a una pérdida de identidad en los centros urbanos.

Si se analiza la evolución de la población extranjera residente en el centro, lo primero que llama la atención respecto a los datos aportados por los Censos de población y viviendas de 2001 y 2011 es el considerable aumento de la población extranjera en esta parte de la ciudad ya que en 2001 eran 1.217 los residentes extranjeros, cifra que se aumenta considerablemente a 3.960 personas, lo que implica un aumento del 225,3\% con respecto al año 2001. 


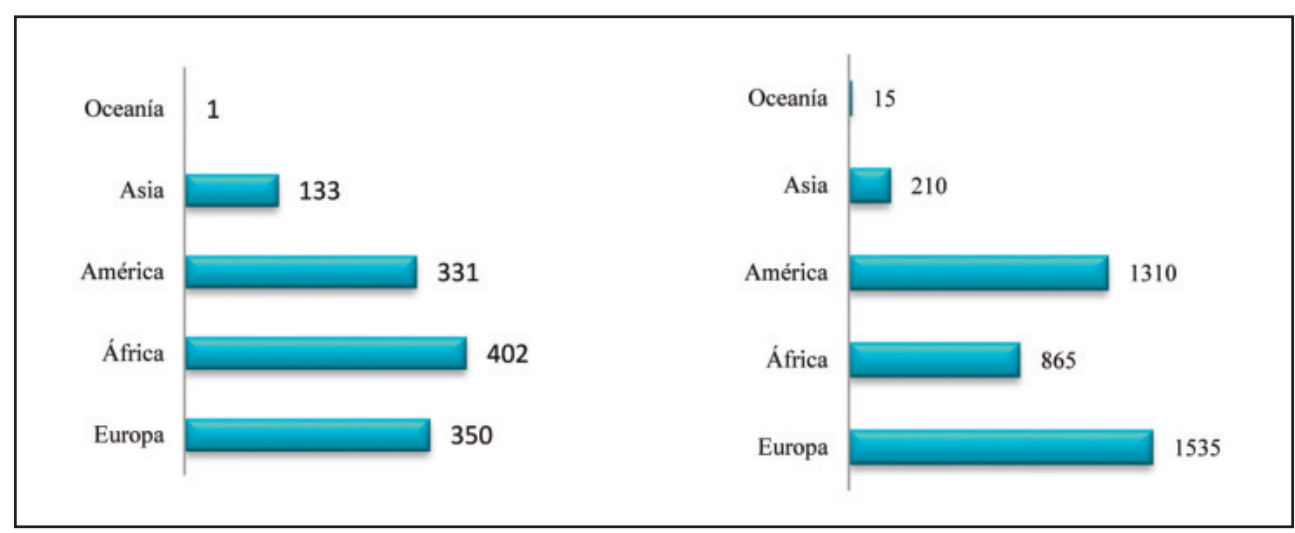

Figura 12. Procedencia de extranjeros en distrito centro (2001-2011).

Fuente: INE. Elaboración propia.

Este aumento significativo no solo se expresa en datos, también se observan tendencias según el origen de procedencia de los extranjeros por los continentes. En este sentido destaca la duplicación de los extranjeros originarios de áfrica pasando de 402 residentes africanos a 865 y un aumento en casi mil extranjeros procedentes del continente americano pasando de 331 en 2001 a 1.310 en 2011 donde 185 pertenecen a América del Norte y 1.125 proceden de América Central y del Sur.

Sin embargo, el aumento más considerable se produce en ciudadanos procedentes del continente europeo, cifra que aumenta casi en 1.200 personas ya que se pasa de 350 personas europeas residentes en el centro en 2001 a 1.535 personas en 2011, de las cuales 1.185 pertenecen a la Comunidad Europea y 380 a europeos de fuera de la Unión Europea. Este dato resulta de especial interés si se observan los países europeos más frecuentes de los residentes europeos (Francia, Reino Unido y Alemania), suelen ser países relacionados directamente con el turismo, con un alto poder adquisitivo que deciden residir en la zona centro de la ciudad contribuyendo a una revaloración urbanística y acentuando las consecuencias económicas que esto puede conllevar.

\subsection{Estructura del hogar y vivienda}

\subsubsection{Estructura del hogar}

Aunque se ha tratado el tema de la vivienda y el hogar en el apartado de los aspectos económicos, resulta de especial relevancia hacer un inciso sobre el hogar y su estructura social, cómo se compone y sus tendencias. En este sentido los procesos de gentrificación no solo constituye cambios económicos, urbanísticos, políticos y demo- 
gráficos, sino que también dichos procesos están impulsados por cambios sociales que suelen venir establecidos por una tendencia hacia un cambio de pautas de comportamiento social. Ya Marcuse menciona la "family gentrification"7 que cumple unos patrones de comportamiento y una tendencia en la zona de Brooklyn, Nueva York. En este sentido, Smith $^{8}$ hace mención al incremento de la demanda de viviendas reducidas motivada por factores sociales y psicológicos destacando el individualismo y los nuevos estilos de vida que a su vez sirven de estímulo para propulsar el desplazamiento de ciertos sectores al centro urbano.

Estamos ante la importancia que supone el análisis social en cuanto a la composición de la estructura de los hogares, algo que puede reflejar la evolución de los estilos de vida de los residentes del centro de la ciudad. El análisis del tamaño del hogar indica la tendencia del estilo de vida vinculado a familias pequeñas, parejas sin hijos $\mathrm{o}$, incluso, a una tendencia al individualismo, la figura siguiente es bastante explicita en esta cuestión.

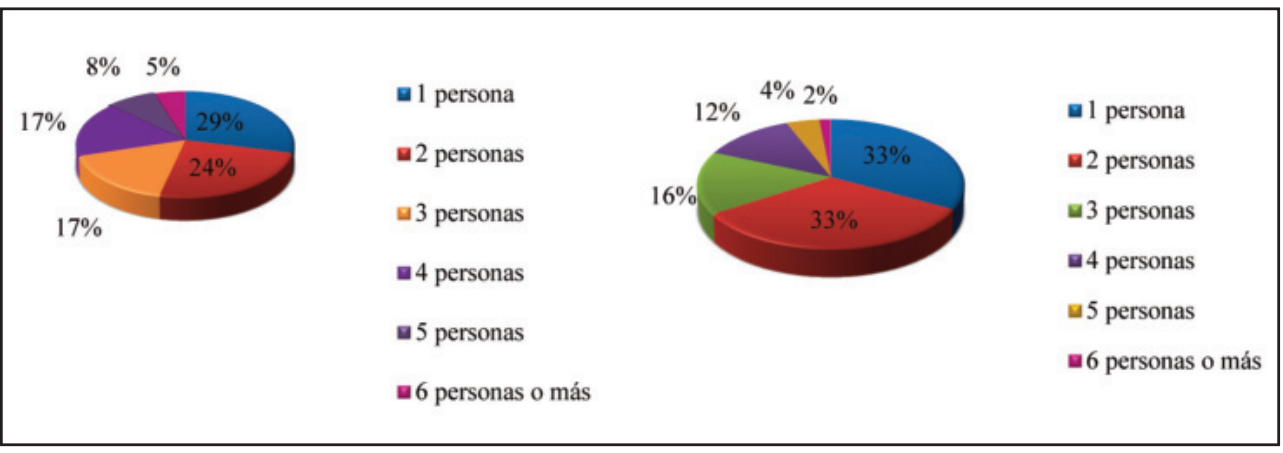

Figura 13. Evolución del tamaño de los hogares en Granada (2001-2011).

Fuente: INE. Elaboración propia.

Además de un aumento considerable de hogares, de 2001 con 18.851 hogares se produce un importante incremento a 23.075 hogares, en este periodo según los Censos de Población y Viviendas se produce una reducción drástica de los hogares numerosos, así por ejemplo los hogares con seis personas o más pasan de 928 hogares suponiendo un 5\% en 2001 a 375 hogares constituyendo un 2\%, lo mismo ocurre con los hogares de cinco personas que pasa con un 8\% y 1.493 unidades a 1045 unidades

7. Marcuse, P.: Abandonment, Gentrification and Displacement: Conexions, causes and Policy Responses in New York City. Urban Law Annual; Journal of Urban and Contemporary Law. Volumen 28. January 1985.

8. Smith, N.: Gentrificación urbana y desarrollo desigual. Espacios críticos. Editorial Icaria. Madrid. 2015 
constituyendo un 4\%. También se produce un cambio significativo en los hogares de cuatro personas cuya cifra se reduce pasando de 3.190 hogares a 2.930, en este caso no constituye una reducción significativa pero sí en cuanto al porcentaje ya que el número de hogares aumenta un $22,4 \%$ con respecto a los hogares de 2001, por lo que la relación proporcional con el resto de los hogares se ve disminuida proporcionalmente con el resto de los hogares pasando de un 17\% de 2001 a un 12\% de 2011. El porcentaje de los hogares de tres personas se mantiene (17\% para 2001 y 16\% para 2011), si bien el número de los hogares de este tamaño se amplia de 3.144 a 3.700 .

Observamos cambios más intensos en la tendencia a los hogares compuestos con pocos miembros, destacando un incremento de los hogares de dos personas que en 2001 se hallaba en 4.651 unidades suponiendo el 24\% del total, mientras que en 2011 dicha cifra se amplía considerablemente hasta 7.720 unidades suponiendo el 33\%. No obstante, el aumento más significativo es el de los hogares de una persona que si en 2001 esa cifra se hallaba en 5.446 suponiendo el 29\%, en 2011 aumenta hasta 7.760 con un 33\%. Aunque el aumento es menor respecto a los hogares de dos personas, sí constituye un síntoma de un cambio de comportamiento social que implica una tendencia hacia el individualismo. Este aumento de los hogares de una y dos personas coincide con el aumento de pisos de una y dos habitaciones en el mismo periodo de tiempo. Los comportamientos que se definen en el centro están vinculados con un tipo de pensamiento y sociedad que posee unas características específicas y que, especialmente en este aspecto, tienden a familias menos numerosas, o incluso al aumento de parejas que forma un hogar o una unidad individual.

Otro de los aspectos relacionados con el factor económico lo constituye el régimen de tenencia ya que es un aspecto ligado intrínsecamente a los fenómenos de gentrificación. Hay que decir que el proceso gentrificación de una ciudad está basado en las leyes de oferta y demanda que se producen al revalorizarse un espacio (Llopis, Sorando y Andura, 2017). Estas dinámicas implican un cambio del régimen de tenencia que generalmente tiende al aumento del alquiler de viviendas. Otro de los aspectos destacables en este sentido lo constituye la especulación, algo que se produce al incrementarse la demanda y reducirse la oferta, ya que tanto el alquiler como la hipoteca se encuentran sometidos a las fluctuaciones de mercado. Si se analiza la evolución del régimen de tenencia de las viviendas en la zona centro de la ciudad de Granada, casi la mitad de las viviendas están pagadas en 2001, tendencia que se reduce en un $8 \%$ ya en el 2011. Otro de los cambios destacables que se produce es el aumento de las hipotecas que se pasa de un 13\% a un 15\%, lo cual indica la demanda social en la zona céntrica. Sin embargo, el aspecto más destacable es el considerable aumento de los alquileres en el centro que se incrementa un 3\% desde 2001. Este tipo de régimen de tenencia está asociado a los nuevos comportamientos sociales respecto a la vivienda. La demanda social de los alquileres constituye uno de los factores más destacables cuando se produce una renovación de un espacio social, y por lo tanto una inversión en la vivienda con el objetivo de ser alquilada y sacar el máximo rendimiento econó- 
mico posible o plusvalía. Esta demanda del alquiler suele estar vinculad al aumento de los precios del alquiler y al encarecimiento del suelo, ya que muchos de los propietarios que se deciden a alquilar su vivienda invierten en la readaptación y rehabilitación de la vivienda con el fin de aumentar el precio del alquiler.

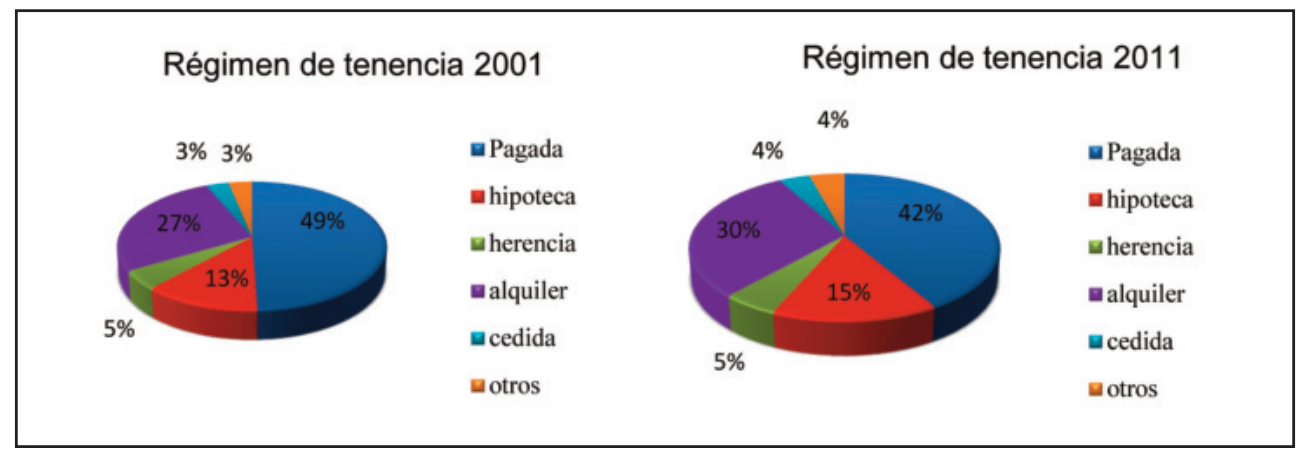

Figura 14. Evolución del régimen de tenencia de la vivienda en Granada (2001-2011).

Fuente: INE. Elaboración propia.

Relacionado con posibles indicadores de gentrificación hemos seleccionado respecto a la mejora en el confort de las viviendas dos: la accesibilidad y el equipamiento de calefacción, en relación al primero conviene destacar una mejora en el porcentaje de viviendas que poseen ascensor en una década (2001-2011).

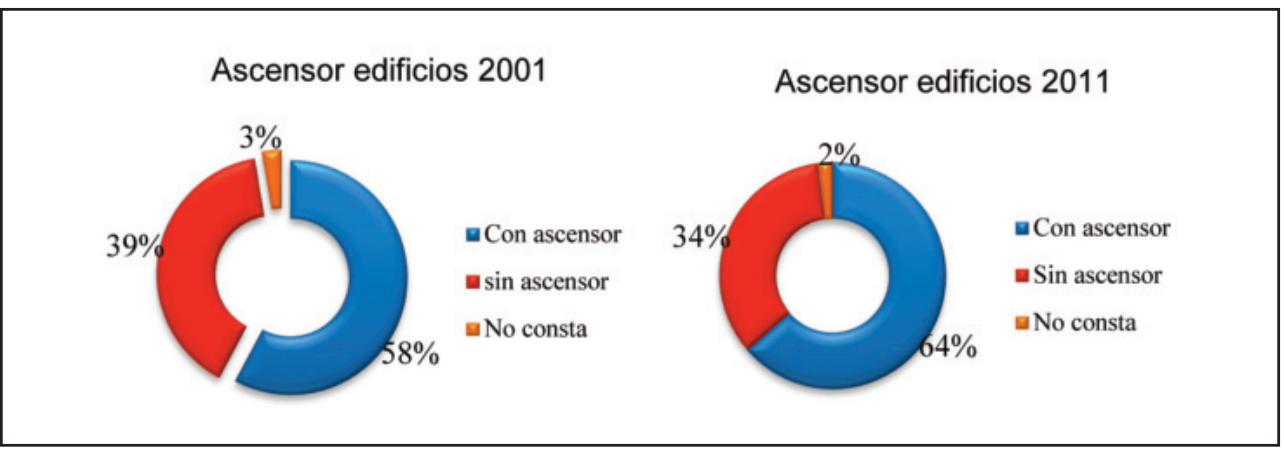

Figura 15. Evolución del equipamiento de ascensores en Granada (2001-2011).

Fuente: INE. Elaboración propia.

La inversión en los edificios se hace patente con la presencia de ascensores que indican un equipamiento demandado por todos los estratos sociales. En 2001 un 39\% de los edificios de viviendas no poseían ascensor, dicha cifra descendía a un 34\% en 2011. 
Por el contrario, los edificios con ascensor pasan de un 58\% a un 64\%. Se produce una importante mejora ya que en 2001 un 72\% de las viviendas poseían algún tipo de dificultad debido a las barreras que dificultaba el acceso, este porcentaje se reduce considerablemente en 2011 situándose en un 55\%, lo que implica que las viviendas con facilidad de acceso aumenten de un 25\% (2001) a un 33\% (2011), el resto del porcentaje pertenece a la categoría no aplicable (3\% y 2\% para 2001 y 2011 respectivamente). Otra de las mejoras que se producen en la vivienda son los aspectos relacionados con la aclimatación de las mismas, se puede observar una mejora en cuanto a la aclimatación, las viviendas sin calefacción se reducen del 13\% al 7\% entre el 2001 al 2011. Por otra parte, destaca la instalación de calefacción individual, este tipo de aclimatación suele estar proveído de gas natural. El establecimiento de gas natural y de calefacción individual implica una importante inversión por parte de los propietarios de las viviendas. Así estas mejoras suponen un incremento de la calidad de vida. Con estos datos la gentrificación no solo supone una mejora, rehabilitación y consecuente revalorización de una zona céntrica urbana sino que implican cambios en las viviendas individuales (Menéndez, 1995). Estas inversiones justifican el aumento de la demanda de un público que busca mejores condiciones de vida, lo cual se relaciona directamente con su poder adquisitivo.

Edificios calefacción 2001

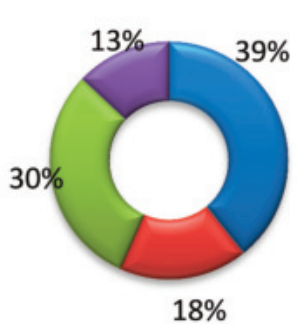

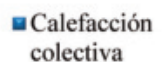

- Calefacción individual

$\square$ Con aparatos

uSin calefacción

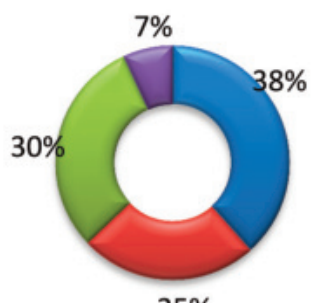

$25 \%$
- Calefacción colectiva

घCalefacción individual

$\backsim$ Con aparatos

घ Sin calefacción

Figura 16. Evolución del equipamiento de edificios con calefacción en Granada (2001-2011). Fuente: INE. Elaboración propia.

\section{Conclusiones}

Uno de los aspectos demográficos más destacables de la zona centro de Granada es el envejecimiento de la población, más sobresaliente en el sexo femenino que en el masculino, lo que indica una mortalidad más acelerada en la población masculina 
(Sánchez, 2005). Aumentan los desplazamientos desde el centro hacia la periferia (Susino y Duque, 2011) de personas con rentas más bajas ya que al producirse un aumento del nivel del vida y de precios de la vivienda tanto en la modalidad comprar como alquiler, los sectores sociales más desfavorecidos han tenido experimentado una proceso de expulsión fuera de la zona central de la ciudad o reagruparse más personas en un mismo hogar cuando se trata de viviendas de alquiler.

Otro de los aspectos a nivel laboral es el aumento de personas activas entre la década de 2001 y 2011. Este aumento determina un mayor dinamismo económico de 2011 con respecto a 2001 a pesar de la crisis surgida en 2008, algo que podría estar relacionado con la profesionalización del centro debido a la cantidad de personas con estudios avanzados y trabajos bien remunerados que residen en el mismo. Sin embargo, uno de los datos más curiosos ha sido el aumento de la tasa de dependencia del centro, esto no implica un aumento de población mayor en diez años (de 11.923 de 2001 a 12.140 de 2011) si no un aumento de población menor de dieciséis años que constituye parte de esa población dependiente de la que está en edad de trabajar. Este rasgo indica un aumento de la población de familias (generalmente con pocos hijos) que residen en el centro con respecto a 2001.

En los procesos de gentrificación, los expertos y autores coinciden en señalar una creciente terciarización que implican trabajos no manuales y una mejor formación relacionada con una profesionalización creciente, como se puede observar, el sector terciario es el más común con diferencia en el centro respecto a otros sectores (el sector primario no tiene incidencia en el centro urbano tampoco lo tiene el sector dedicado a la construcción, contrariamente a los datos analizados de la población que reside en la periferia). Durante el periodo 1991-2011 se produce un aumento del sector terciario. El incremento de este sector y sus trabajadores no es solo un producto de los procesos gentrificadores, sino que forma parte de una evolución de la dinámica de la evolución histórica en los centros urbanos de cualquier ciudad. Históricamente, los centros de las ciudades estaban constituidos por zonas artesanales, las cuales se fueron desplazando hacia las periferias buscan una mayor espacio donde poder acceder a las fases de industrialización que necesitan unos espacios mayores y con precios competitivos.

¿Pero se podría hablar de una terciarización como producto de una gentrificación en el centro de Granada? Según los datos analizados, el aumento del sector terciario simplemente obedece a dinámicas propias de países desarrollados y entornos urbanos, esto no implica una total desvinculación con los procesos de gentrificación. Por lo tanto se podría hablar de un proceso recíproco donde son muchos los factores que influye, pero no se puede hablar de una asociación terciarización-gentrificación directa y tampoco de procesos de participación ciudadana en el proceso (Gutiérrez, 2016).

En los aspectos relacionados con la morfología urbana, se observan importantes transformaciones como serían la llegada de un comercio cuya principal seña de identidad 
son las franquicias frente al comercio tradicional existente que en parte ha sido sustituido. La realización de obras de renovación urbana y la rehabilitación de edificios es otro importante indicador en estos procesos de cambios, es destacable el acondicionamiento de edificios con calefacción y aire acondicionado, también la instalación de ascensores que permiten una mejora en la accesibilidad a edificios que presentan una edad cronológica en muchos casos superior a cincuenta años, en todo caso la rehabilitación urbana repercute en un importante cambio social en distintas ciudades españolas (Leal y Sorado, 2013) y para el caso de Granada también existe esta tendencia.

\section{Bibliografía}

Abellán Bordallo, J., 2014. Ciudad, crisis y desobediencia. Una aproximación a las luchas por la vivienda en Madrid. La ciudad neoliberal: Gentrificación y exclusión en Santiago de Chile, Buenos Aires, Ciudad de México y Madrid / coord. por Hidalgo Dattwyler, R.; Janoschka, M., ISBN 9789561413955, págs. 257-274.

Aguilera, M.J. y Otros, 2003. Fuentes, tratamiento y representación de la información geográfica. Ed. UNED. (Unidades didácticas). Madrid, 421 pp.

Alba Sargatal, M., 2001. Gentrificación e inmigración en los centros históricos: el caso del Raval de Barcelona. Scripta Nova: Revista electrónica de geografía y ciencias sociales, ISSN-e 1138978, №. Extra 5, 94, (Ejemplar dedicado a: Migración y cambio social: III Coloquio Internacional de Geocrítica).

Arbaci, S., Rae, I., 2014. Efecto barrio y desigualdades, evidencias para desmitificar las politicas urbanas de diversificación residencial. ACE: architecture, city and enviroment, ISSN-e 18864805, № 26, págs. 147-176.

Benach, N., Albert I Mas, A., 2011. La gentrificación como una estrategia global. Papers: Región Metropolitana de Barcelona, ISSN-e 2013-7959. №60, 2011 (Ejemplar dedicado a: Gentrificació i dret a la ciutat), págs. 17-23.

Bosque Sendra, J., Bosque Maurel, J., Gutiérrez, F., 1993. Atlas social de la ciudad de Granada. Problemas para su elaboración. Granada. Serie Geográfica, vol. 3.

Bosque Maurel, J., 1988. Geografia urbana de Granada. Archivum.Ed. Universidad de Granada.

Bourne, L.S., 1993. The myth and the reality of gentrification: A commentary on emerging urban forms. StudiesJournal, № 30, págs. 183-189.

Butler, T., 2007. Gentrificación. Ciudades en transformación: reconsideración de la competitividad, la cohesión y la gobernabilidad urbanas/ coord. por Gordon, I; Buck, N.; Hardin, A.; Turok, I. IBSN 978-84-451-3075-9, págs. 157-171.

Castells, M., 1993. The City and the Grassroots: A Cross-cultural Theory of Urban Social Movements. Ed. Edward Arnold. London.

Compán Vázquez, D., Sánchez González, D., 2005. Los ancianos al desván. El proceso de degradación biológica y social de la población mayor del municipio de Granada. Granada. Cuadernos geográficos de la Universidad de Granada. ISSN 0210-5462, № 36, págs. 255-274. 
Díaz Parra, I., 2011. Desplazamiento, acoso inmobiliario y espacio gentrificable en el caso de Sevilla. Encrucijadas: Revista Crítica de Ciencias Sociales, ISSN-e 2174-6753, № 2, (Ejemplar dedicado a: Espacios Urbanos: perspectivas y conflictos), págs. 48-68.

Díaz Parra, I., 2014. La gentrificación, un regreso a la ciudad de la intervención urbanística. Boletín de la Asociación de Geógrafos Españoles, ISSN 0212-9426, № 64, págs. 321-340.

Díaz Parra, I., 2013. Gentrificación y disciplinamiento en los centros históricos. La creación de un espacio seguro y atractivo en San Luis-Alameda (Sevilla). La ciudad, un espacio para la vida: miradas y enfoques desde la experiencia espacial/ coord. por Sánchez González, D.; Egea Jiménez, C., ISBN 978-84-338-5557-2, págs. 75-92.

Díaz Parra, I., 2009. Procesos de gentrificación en Sevilla en la coyuntura reciente. Análisis comparado de tres sectores históricos: San Luis-Alameda, Triana y San Bernardo (2000-2006). Scripta Nova. Revista electrónica de Geografía y Ciencias Sociales. Universidad de Barcelona. ISSN: 1138-9788. Depósito Legal: B.21.741-98. Vol. XUUU, núm. 304,

Díaz Parra, I., 2015. Viaje solo de ida. Gentrificación e intervención urbanística en Sevilla. EURE: revista latinoamericana de estudios urbanos regionales. ISSN 0250-7161, ISSN-e 0717-6236, № 122, págs. 145-166.

Donzelot, J., 2004. La ville à trois vitesses: relegation, périurbanisation, gentrification. Esprit. № 303 (3/4) Mars-Avril, pp. 14-39.

Duque Calvache, R., 2016. Procesos de gentrificación en cascos antiguos: el Albaicín de Granada. Colección Monografías, núm. 301. Centro de Investigaciones Sociológicas. Madrid.

Feria Toribio, J.M., 2015. Los modelos de organización y dinámicas espaciales metropolitanas en Andalucía. Cuadernos geográficos de la Universidad de Granada, ISSN 0210-5462, Vol. 54, № 2, págs, 196-219.

Fernández Gutiérrez, F., Jiménez Bautista, F., 2005. Problemática de la población en el centro bistórico de Granada. Alicante. Biblioteca Virtual Miguel de Cervantes.

Fion Arantes, O.B., 2016. Gentrificación estratégica. RevisArquis. ISSN 2215-275X. Universidad de Costa Rica.

Friedberger, M., 1996. Rural Gentrification and Livestock Raising: Texas as a Test Case, 1940-1995. Ruralhistory. Volume 7, Issue 1, págs. 53-68.

García Castaño, J., Ramos, E., Salvadó, T., Sorando, D., 2017. Destrucción creativa y disputa de los centros urbanos. Minerva: Revista del Círculo de Bellas Artes, ISSN 1886-340X, № 28, págs. 45-50.

García Pérez, E., 2014. Gentrificación en Madrid. Revista de Geografía Norte Grande. ISSN-e 07183402, № 58, págs. 71-91.

García Pérez, E., Sequera, J., 2013. Gentrificación en centros urbanos. Aproximación comparada a las dinámicas de Madrid y Buenos Aires. Quid 16: Revista del Área de Estudios Urbanos, ISSN-e 2250-4060, № 3, (2013. (Ejemplar dedicado a: "Ciudades neoliberales": políticas urbanas, diseño y justicia social), págs. 49-66.

Gómez Carmona, G., VIllar Calvo J.A., 2015. Impactos de lo global en lo local: Gentrificación en ciudades latinoamericanas. Revista de Urbanismo, Universidad de Chile. ISSN: 0717-5051. № 32. 
Guadalupe Valiñas, M., 2016. Gentrificación y mercado inmobiliario, destrucción creativa y modificación del espacio urbano social. Academia XXII: revista semestral de investigación, ISSNe 2007-252X, Vol. 7, № 14, págs. 99-111.

Gutiérrez Sánchez, V.M., 2016. La participación ciudadana como forma de resiliencia ante la gentrificación de los centros históricos. Historic Towns between East: ciudades históricas entre Oriente y Occidente / coord. Por Niglio, O., ISBN 978-88-6975-081-6, págs. 73-83.

Hackworth, J., Smith, N., 2000. The Changing State of Gentrification. Tijdschriftvoor Economische Sociale Geografie, 92 (4), pp. 465-477.

Hamnett, C., 2003. Gentrification and the Middle-class Remaking of Inner London, 1961-2001. UrbanStudies, Vol. 40, № 12, 2401-2426, November 2003.

Hiernaux-Nicolas, D., González Gómez, C.I., 2014. Turismo y gentrificación, pistas teóricas sobre una articulación. Revista de Geografía Norte Grande. ISSN-e 0718-3402, № 58, págs, 55-70.

Jerez, C., 2002. La forma del centro histórico de Granada. Morfología urbana, tipología edificatoria y paisaje urbano. Universidad de Granada.

Leal Maldonado, J., Sorado Ortín, D., 2013. Rehabilitación urbana y cambio social en las grandes ciudades españolas. Revista Aragonesa de Administración Pública. ISSN 1133-4797, № Extra 15, (Ejemplar dedicado a: Rehabilitación y regeneración urbana en España), págs. 205-236.

Lebreton, A., Mougel, G., 2008. La gentrification comme articulation entre forme urbaine et globalisation. Espaces et sociétés. ISSN 0014-0481, № 132-133, (Ejemplar dedicado a: La gentrification urbaine), págs. 57-74.

Lees, L., Slater, T., Wyly, E., 2008. Gentrification. Ed. Routhledge. London.

Lehman Frich, S., 2008. Gentrifieurs, gentrifies cohabiter dans le quartier de la Mission (San Francisco). Espaces et sociétés. ISSN 0014-0481, № 132-133 (Ejemplar dedicado a: La gentrification urbaine), págs. 143-162.

Ley, D., 2003. Artists, Aestheticisation and the Fiel of Gentrification. CarfxPublishing. UrbanStudies, Vol. 40, № 12, pp. 2527-2544,

Lloplis, E., Sorando Ortín, D., Ardura Urgiaga, A., 2017. Gentrificación. De un barrio popular a distrito burgués. El Viejo topo. ISSN 0210-2706, № 352, págs. 30-35.

Marcuse, P., 1985. Abandonment, Gentrification and Displacement: Conexions, causes and Policy Responses in New York City. Urban Law Annual; Journal of Urban and Contemporary Law. Volumen 28. January 1985.

Menéndez Collantes, M., 1995. La rehabilitación urbana en la ciudad de Granada. Cuadernos geográficos de la Universidad de Granada. ISSN 0210-5462, № 24-25, 1995, págs. 139-166.

Muñoz Carrera, O., 2009. El proceso gentrificador en el municipio de Madrid (1996-2001). Igualdad, desarrollo y cooperación: 13, 14 y 15 de noviembre de 2009, Palacio de los Condes de Valdeparaíso, Almagro (Ciudad Real) / coord. Gallego Trijueque, S.; Gómez Escarda, M., 2009, ISBN 978-84-692-6633-5, págs. 317-332.

Perren, J., Cabezas, S., 2016. Observatorio Metropolitano. El mercado contra la ciudad. Globalización, gentrificación y políticas urbanas, Madrid. Traficantes de sueños. Revista Rey Desnudo: Revista de Libros, ISSN-e 2314-1204, Vol. 4, № 8.(Ejemplar dedicado a: Otoño), págs. 71-83. 
Philips, M., 2004. Other geographies of gentrification. Progress in Human Geography.Vol. 28, Issue 1 , págs. 5-30.

Reyes, M.A., 2017. El proceso de revitalización del Centro Histórico de Granada. Revista Encuentro. ISSN 0424-9674, pág. 62.

Rodríguez Rodríguez, V., Vázquez Varela, C., Puga González, M.D., 2002. Bases para el estudio de la gentrificación en Madrid. Boletín de la Real Sociedad Geográfica, ISSN 0210-8577, № 137-138, págs. 273-310.

Romero Romero, D., Romero Morato, A., 2017. Hacia un modelo de detención temprana de procesos de gentrificación. Jornadas Periferias Urbanas, la regeneración integral de barriadas residenciales obsoletas: libro de capítulos, ISBN 978-84-617-9003-6, págs. 169-183.

Ruiz Ruiz, M., Barbosa García, M.V., 1997. El centro bistórico de Granada, evolución del casco antiguo de la ciudad. Información genérica. Granada: Gabinete Pedagógico de Bellas Artes, D.L. ISBN 84-89502-22-6.

Sánchez González, D., 2005. El Proceso de envejecimiento demográfico en Granada y su área metropolitana. Universidad de Granada. Cuadernos Geográficos, 37, pp. 185-199.

Sargatal Bataller, M.A., 2000. El estudio de la gentrificación. Revista Bibiliográfica y Geografía y Ciencias Sociales. Universidad de Barcelona. ISSN 1138-9796. № 228.

Sequera, J., 2015. A 50 años del nacimiento del concepto "gentrificación". La mirada anglosajona. Revista Bibliográfica de geografía y ciencias sociales. Universidad de Barcelona. ISSN: 1138-9796. Vol. XX, núm. 1.127.

Sequera, J., 2014. Gentrificación en el centro histórico de Madrid, el caso de Lavapiés. La ciudad neoliberal: Gentrificación y exclusión en Santiago de Chile. Buenos Aires. Ciudad de México y Madrid/ Coord. Hidalgo Dattwyler, R.; Janoschka, M.. ISBN 9789561413955, págs. 233-255.

Slater, T., 2006. The Eviction of Critical Perspectives from Gentrification Research. International Journal of Urban and Regional Research. Volumen 30.4. December, p. 752.

Smith, N., 2015. Gentrificación urbana y desarrollo desigual. Espacios críticos. Editorial Icaria. Madrid.

Sorando Ortín, D., Ardura Urquiaga, A., 2018. Proceso y dinámicas de gentrificación en las ciudades. Papers: Regió Metropolitana de Barelona, ISSN-e 2013-7959, № 60, (ejemplar dedicado a: Gentrificació i dret a la ciutat), págs. 34-47.

Susino Arbucias, J., Duque Calvache, R., 2011. Medir la movilidad residencial intraurbana: Gentrificación en un barrio de Granada. Población y espacios urbanos: XII Congreso de Población Española, Barcelona, coord. Por Pujadas Rúbies, I.; Bayona Carrasco, J.; García Coll, A.; Gil Alonso, F.; López Villanueva, C.; Sánchez Aguilera, D.; Vidal i Bendito, T. 2011, ISBN 978-85-694-2666-1, págs. 431-446.

Valencia Palacios, M.A., 2010. Deterioro del tejido urbano en áreas centrales. Experiencias programáticas de regeneración habitacional. DU \& P: Revista de diseño urbano y paisaje. ISSNe 0717-975, Vol. 7, № 19.

Zárate Martín, M.A., 2012. Geografía urbana. Dinámicas locales, procesos globales. Madrid. Editorial Ramón Areces. 2012. 